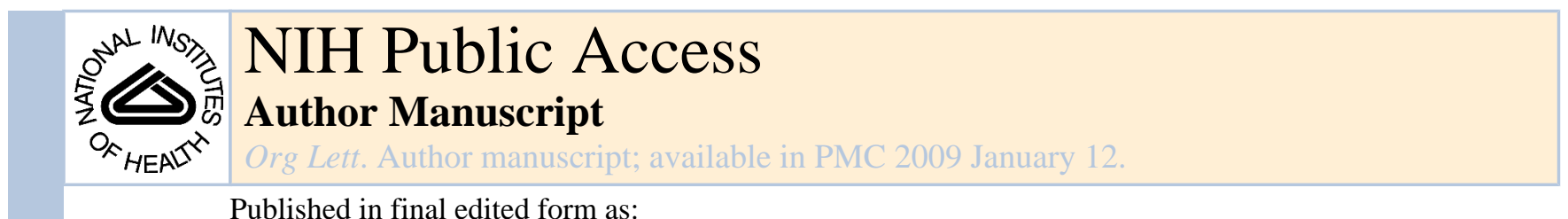

Published in final edited form as:

Org Lett. 2007 November 22; 9(24): 5027-5029. doi:10.1021/ol702247a.

\title{
Synthesis of the ABC- and D-Ring Systems of the Indole Alkaloid Ambiguine G
}

\author{
Aroop Chandra, Rajesh Viswanathan ${ }^{\dagger}$, and Jeffrey N. Johnston \\ Department of Chemistry \& Vanderbilt Institute of Chemical Biology, Vanderbilt University, Nashville, TN \\ $37235-1822$
}

\section{Abstract}<smiles>C=CC12C=C(C#N)C(C)(C)c3[nH]c4cccc(c4c31)C1(C)C=C2C(C)(C)C(Cl)C1</smiles>
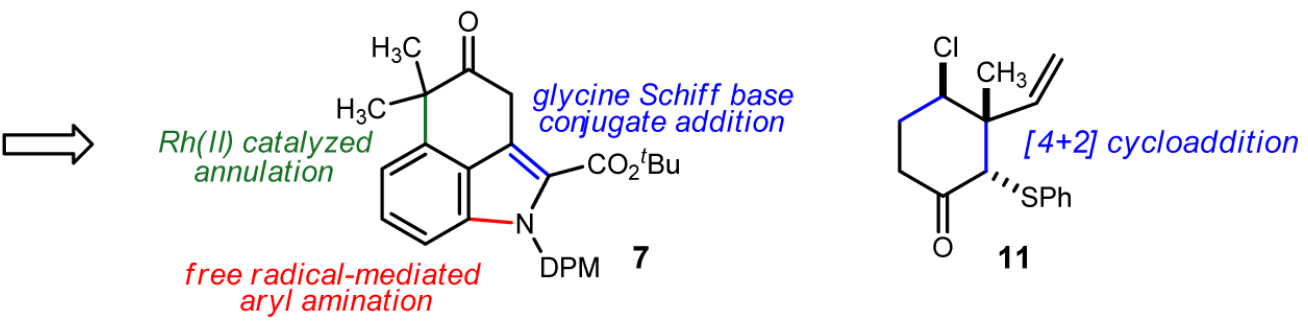

(+)-ambiguine G (1)

A glycine Schiff base Michael addition is used in sequence with free radical-mediated aryl amination to ultimately arrive at the ambiguine G ABC-tricycle convergently. Additionally, thermal DielsAlder cycloaddition of $\beta$-chloro methacrolein with Cohen's diene is used to diastereoselectively construct the D-cyclohexane ring bearing a neopentyl chloride.

The blue-green algae Hapalosiphon delicatulus produces a variety of indoloterpenes, including the hapalindole, ${ }^{1}$ fischerindole, ${ }^{2}$ and welwitindolinone ${ }^{3}$ classes of natural products (Figure 1). The ambiguines have been isolated from this source as well, appearing formally as prenylated hapalindoles, and often bearing an additional element of complexity in the form of a fifth (fused) seven membered ring (e.g. ambiguine G, 1). ${ }^{4}$ The entanglement between structural diversity and apparent homology within these natural products has led to the proposal that the individual biosynthesis pathways may overlap.

In contrast to total syntheses within the first three classes, 5,6 the pentacyclic ambiguines and their highly ring-fused skeletons remain without approach, much less a synthetic solution. Ambiguine G (1) further attracted our attention by virtue of the challenge it poses on a strategic level to the development of a convergent synthesis. Of the nineteen atoms that comprise the structural core, eight (42\%) are involved in ring fusions. This uncharacteristically high level of ring interdependence provides a unique challenge for traditional annulation approaches whose implementation might result in a rather linear approach. Figure 2 outlines the key elements of a global solution to this problem. Instead of reliance on an indole template, we targeted instead the construction of the BC-rings by a Buchner reaction, ${ }^{7}$ followed by selective fragmentation of the norcaradiene intermediate. The A-ring would then be annulated using a

jeffrey.n.johnston@vanderbilt.edu.

${ }^{\top}$ Current address: Department of Chemistry, University of Utah, Salt Lake City, UT 84102. 
sequence of carbon-carbon and aryl-nitrogen bond formations. Separately, we sought a means to validate the use of a Diels-Alder cycloaddition to establish the chiral chlorocyclohexane.

We targeted intermediate $\mathbf{4}$ as a template for design of a convergent indoline annulation. Our plan was to combine the operationally mild nature of free radical-mediated aryl amination 89 with conjugate addition of a glycine Schiff base (5) to a suitably functionalized $\beta$-tetralone (4).

ortho-Bromobenzyl acetic acid (2) was homologated to $\alpha$-diazo ketone 3 in $88 \%$ overall yield by treatment of the derived acid chloride with diazomethane. This intermediate was then treated with rhodium(II) acetate at elevated temperature to effect a formal aryl C-H insertion, proceeding through the intermediate norcaradiene and regioselective cyclopropane ring opening to deliver the $\beta$-tetralone. ${ }^{10}$ Regioselective dimethylation at the more acidic benzylic methylene could be effected in $71 \%$ yield using potassium tert-butoxide in tert-butanol and methyl iodide in slight excess. ${ }^{11}$ Treatment of this intermediate with IBX in a DMSO-toluene binary solvent mixture led in $65 \%$ yield to the key enone $4 .{ }^{12}$

Schiff base $\mathbf{5}$ - now available commercially, or prepared in one step from benzophenone imine and $\alpha$-chloro tert-butyl acetate ${ }^{13}$ - adds to enone $\mathbf{4}$ under conditions of standard phase transfer catalysis to deliver the product of Michael addition in 79\% isolated yield, and as a single diastereomer as observed by ${ }^{1} \mathrm{H}$ NMR of the crude reaction mixture. We did not determine the relative stereochemistry since the two chiral centers would not be preserved in the targeted intermediate. Conversion of the aryl bromide to the derived indoline proceeded as anticipated after application of standard radical generating conditions $\left({ }^{n} \mathrm{Bu}_{3} \mathrm{SnH}, \mathrm{AIBN}, 90{ }^{\circ} \mathrm{C}\right)$. The isolated yield of the intermediate indoline was $66 \%$, and notably, the reduced aryl halide amounted to no more than $5 \%$ of the crude reaction mixture when it could be detected. The indoline was immediately oxidized to the desired intermediate 7 through the application of DDQ in benzene-ethyl acetate at $80^{\circ} \mathrm{C}$. In this manner, indole 7 was retrieved in $60 \%$ yield in addition to $20 \%$ of unreacted indoline.

A solution to the construction of the stereochemically rich D-ring of ambiguine $\mathrm{G}$ has also been developed. This region of the indoloterpene natural products of interest here is a substructure with functional and stereochemical diversity (Figure 1). The vicinal presentation of a chlorine atom and gem-methyl/vinyl arrangement is identical between ambiguines D and $\mathrm{G}$, whereas hapalindole $\mathrm{L}$ and welwitindolinone A present a diastereomeric relationship. In only the total synthesis of hapalindole $G$ has this substructure been addressed. Specifically, the Fukuyama route began from (-)-carvone and in 9 steps converted the $\alpha$-methyl enone to a neopentyl chloride by way of a stereospecific cyclopropane ring opening by chloride.

Our initial solution to the stereocontrolled construction of this subunit utilizes the Diels-Alder cycloaddition shown in Scheme 2. We first prepared the requisite $\beta$-chloro methacrolein 8 using the Arnold synthesis. ${ }^{14}$ In practice however, we were unable to obtain consistent outcomes during our attempts to increase the scale of the preparation. As an alternative, we modified the procedure developed by Williard to convert methallyl chloride to $E$-enal $\mathbf{8}$ in 4 steps. ${ }^{15}$ Following the final oxidation with manganese dioxide, the olefin isomers were converged to desired $E-\mathbf{8}$ by treatment with $p$-toluene sulfonic acid. This aldehyde is best prepared just prior to the Diels-Alder cycloaddition, as some decomposition was noted during storage.

Among the possible dienes we considered to establish the feasibility of this approach, Cohen's diene ${ }^{16}(9)$ emerged as one of the most promising candidates for two reasons: 1) Cohen's demonstration that a sulfur substituent can direct regioselectivity in the cycloaddition was expected to facilitate this rather demanding cycloaddition, ${ }^{17}$ and 2) its influence would be opposite that of the 2-methoxy substituent, a group that we anticipated would simulate the 
electronic effect of the indole nitrogen in the diene derived from 7 . The thiophenyl substituent might be similarly incorporated when transforming 7 to a derived diene, should enhancement of regiocontrol be necessary, and its presence in the product would be used to facilitate final functionalization.

The Diels-Alder cycloaddition of Cohen's diene to $\beta$-chloro methacrolein proceeds thermally, delivering a $44 \%$ isolated yield of the desired secondary chloride 10 after 40 hours at $140{ }^{\circ} \mathrm{C}$. The cycloaddition itself is very selective as we were only able to detect the regioisomer as the minor product in a 3:1 ratio. This ratio is similar to that observed when using acrylonitrile (7:1). 17 The cis relationship (endo) was determined by NOE measurements, with the methyl and allylic methine exhibiting 5\% enhancement, and the aldehyde and chloromethine exhibiting a nearly $10 \%$ enhancement.

The modest isolated yield is due to the known propensity for the Z-vinyl ether to isomerize to the thermodynamically favored, yet unreactive, $E$-olefin. This process, as well as diene polymerization can be retarded by the addition of Hünig's base and a radical inhibitor. Additional precautions were found to improve reproducibility, and these included deoxygenation of the reaction mixture, and silylation of the reaction glassware. There is clearly room for optimization, however the immediacy with which the desired relative stereochemistry can be established is attractive. Further conversion of the aldehyde to a terminal olefin (Scheme 2) was accomplished in $51 \%$ yield by treatment with methyl phosphonium ylide. Cleavage of the methyl enol ether using sodium iodide/trimethyl silyl chloride ${ }^{18}$ furnished the $\alpha$-phenylthio cyclohexanone $\mathbf{1 1}$ in $58 \%$ yield.

In summary, the basis for a solution to a convergent total synthesis of ambiguine $G$ and its congeners has been developed. Key elements of this report include the use of Cohen's diene and a chlorinated methacrolein to establish the chiral chlorocyclohexane. Additionally, free radical-mediated aryl amination was employed as a key step in a three step sequence to generate the tricyclic indole required for many of the natural products in this class (Figure 1). This strategy may ultimately find broader application as an alternative to indole synthesis when mild conditions are required.

\section{Supplementary Material}

Refer to Web version on PubMed Central for supplementary material.

\section{Acknowledgment}

We are grateful to the National Institutes of Health for support of this work (GM-63557). J.N.J. is a recipient of the Eli Lilly Grantee Award.

\section{References}

1. Moore RE, Cheuk C, Yang XQG, Patterson GML, Bonjouklian R, Smitka TA, Mynderse JS, Foster RS, Jones ND, Swartzendruber JK, Deeter JB. J. Org. Chem 1987;52:1036.

2. Park A, Moore RE, Patterson GML. Tetrahedron Lett 1992;33:3257.

3. Stratmann K, Moore RE, Bonjouklian R, Deeter JB, Patterson GML, Shaffer S, Smith CD, Smitka TA. J. Am. Chem. Soc 1994;116:9935.

4. Smitka TA, Bonjouklian R, Doolin L, Jones ND, Deeter JB, Yoshida WY, Prinsep MR, Moore RE, Patterson GML. J. Org. Chem 1992;57:857.Huber U, Moore RE, Patterson GML. J. Nat. Prod 1998;61:1304. [PubMed: 9784177]

5. Hapalindoles J,M,O,H,U:Muratake H, Natsume M. Tetrahedron 1990;46:6331.Sakagami M, Muratake H, Natsume M. Chem. Pharm. Bull 1994;42:1393.Muratake H, Kumagami H, Natsume M. Tetrahedron 1990;46:6351.Hapalindole Q:Vaillancourt V, Albizati KF. J. Am. Chem. Soc 
1993;115:3499.Kinsman AC, Kerr MA. Org. Lett 2001;3:3189. [PubMed: 11574027]Hapalindole G:Fukuyama T, Chen XQ. J. Am. Chem. Soc 1994;116:3125. Welwitindolinone A, fischerindoles I,G:Baran PS, Richter JM. J. Am. Chem. Soc 2005;127:15394. [PubMed: 16262402]Welwitindolinone A:Reisman SE, Ready JM, Hasuoka A, Smith CJ, Wood JL. J. Am. Chem. Soc 2006;128:1448. [PubMed: 16448105]

6. Selected reports toward these natural product classes:MacKay JA, Bishop RL, Rawal VH. Org. Lett 2005;7:3421. [PubMed: 16048307]

7. Buchner E. Ber 1896;29:106.Ye T, Mckervey MA. Chem. Rev 1994;94:1091.Maas G. Top. Curr. Chem 1987;137:75.

8. Johnston JN, Plotkin MA, Viswanathan R, Prabhakaran EN. Org. Lett 2001;3:1009. [PubMed: 11277782]Viswanathan R, Mutnick D, Johnston JN. J. Am. Chem. Soc 2003;125:7266. [PubMed: 12797800]Viswanathan R, Prabhakaran EN, Plotkin MA, Johnston JN. J. Am. Chem. Soc 2003;125:163. [PubMed: 12515518]Srinivasan JM, Burks HE, Smith CR, Viswanathan R, Johnston JN. Synthesis-Stuttgart 2005:330.

9. Free radical-mediated vinyl amination:Nugent BM, Williams AL, Prabhakaran EN, Johnston JN. Tetrahedron 2003;59:8877.Prabhakaran EN, Nugent BM, Williams AL, Nailor KE, Johnston JN. Org. Lett 2002;4:4197. [PubMed: 12443057]

10. Cordi AA, Lacoste JM, Hennig P. J. Chem. Soc. Perkin Trans. 1 1993:3.Dias HVR, Browning RG, Richey SA, Lovely CJ. Organometallics 2005;24:5784.Lovely CJ, Browning RG, Badarinarayana V, Dias HVR. Tetrahedron Lett 2005;46:2453.

11. Gorka A, Hazai L, Szantay C, Hada V, Szabo L, Szantay C. Heterocycles 2005;65:1359.

12. Nicolaou KC, Gray DLF, Montagnon T, Harrison ST. Angew. Chem. Int. Ed 2002;41:996.

13. Eils, S.; Rossen, K.; Jahn, W.; Klement, I. Eur. Patent. 1207151. 2002. Siebum AHG, Woo WS, Lugtenburg J. Eur. J. Org. Chem 2003:4664.

14. Arnold T, Zemkicka J. J. Collect. Chem. Comm 1959:2385.

15. Williard PG, Delaszlo SE. J. Org. Chem 1985;50:3738.

16. Cohen T, Ruffner RJ, Shull DW, Fogel ER, Falck JR. Org. Synth 1988;59:202.Cohen T, Mura AJ, Shull DW, Fogel ER, Ruffner RJ, Falck JR. J. Org. Chem 1976;41:3218.

17. Cohen T, Ruffner RJ, Shull DW, Daniewski WM, Ottenbrite RM, Alston PV. J. Org. Chem 1978;43:4052.

18. Kosarych Z, Cohen T. Tetrahedron Lett 1980;21:3959.Jung ME, Lyster MA. J. Org. Chem 1977;42:3761. 


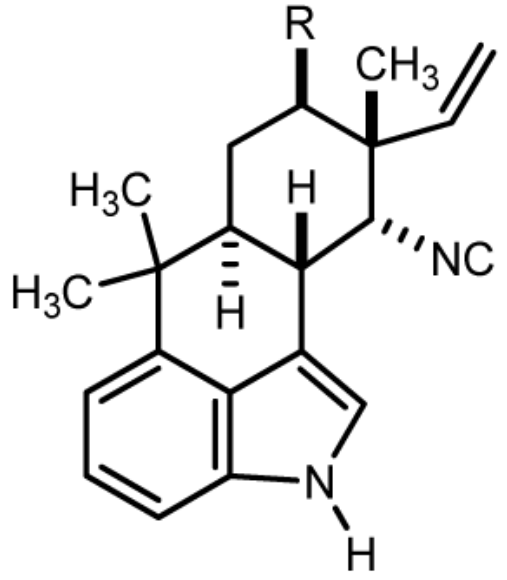

$\mathrm{R}=\mathrm{Cl}$, (-)-hapalindole $\mathrm{G}$ $\mathrm{R}=\mathrm{H},(-)$-hapalindole $\mathrm{U}$

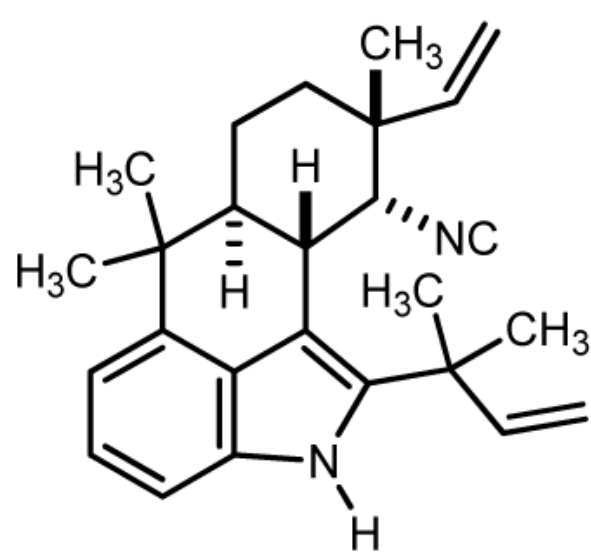

(+)-ambiguine $\mathrm{H}$

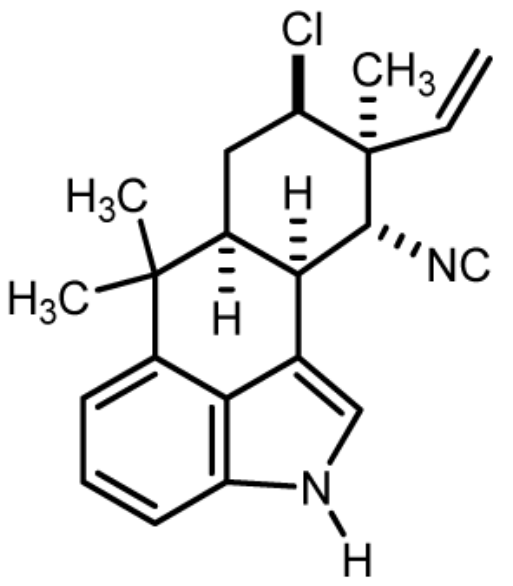

(-)-hapalindole L

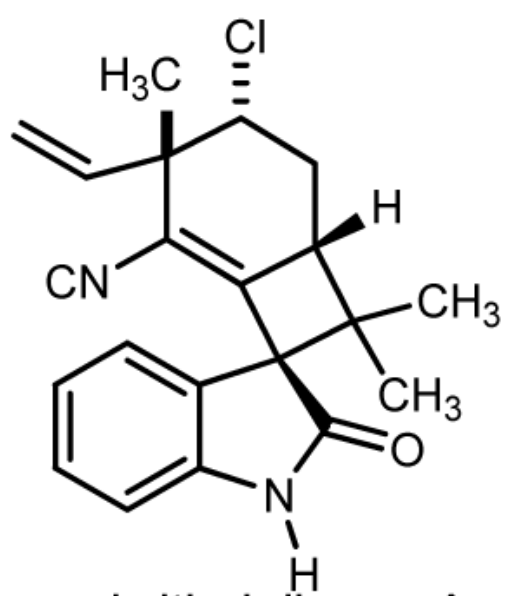

welwitindolinone $A$

Figure 1.

Representative alkaloids from cyanobacteria. 


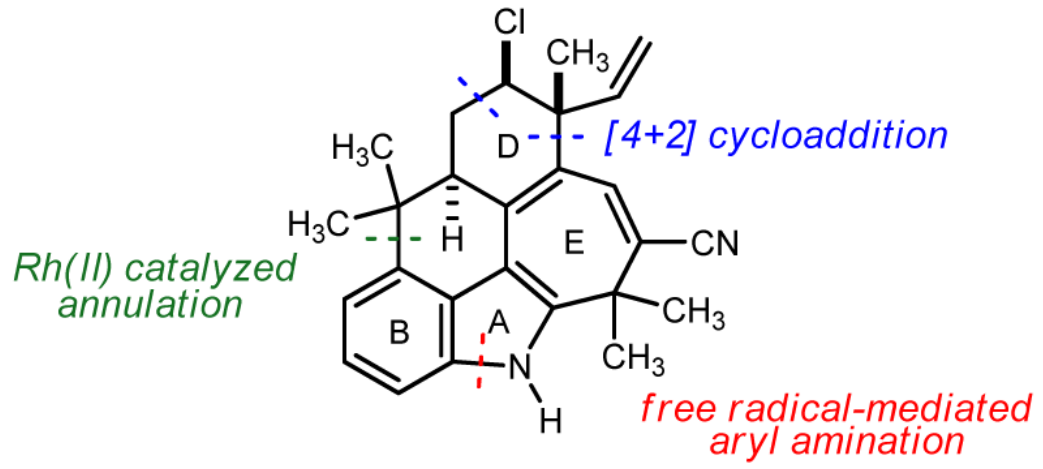

(+)-ambiguine G (1)

Figure 2.

Ambiguine G: key retrosynthetic disconnections. 


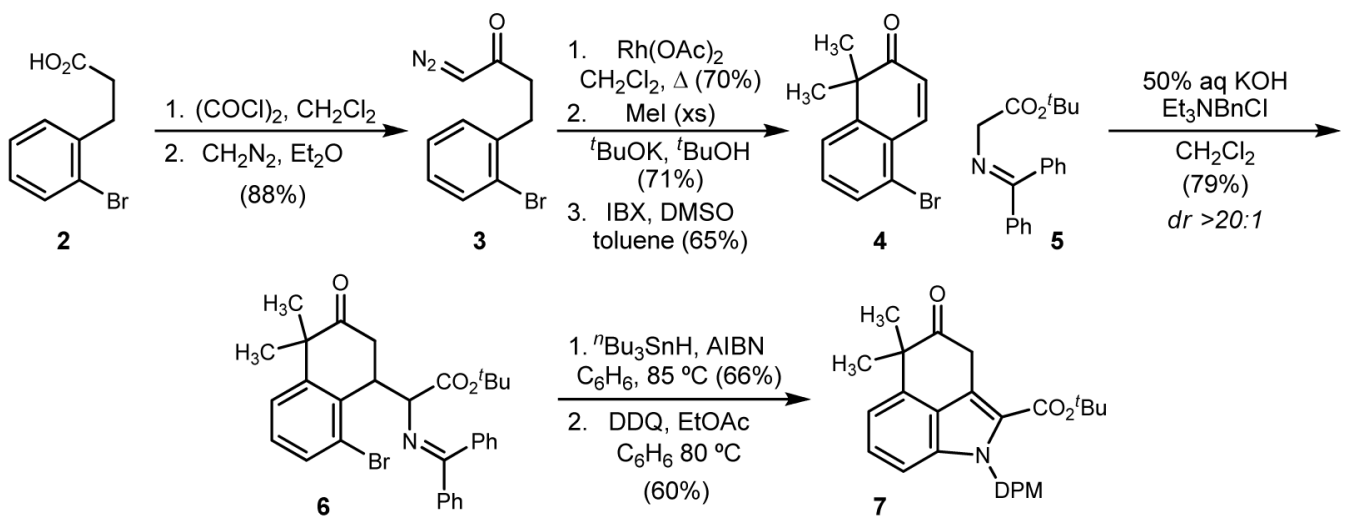

Scheme 1.

Preparation of the the ABC tricycle using a free radical-mediated amination based indoline annulation. 
<smiles>C=C/C(=C\c1ccccc1)OC</smiles>

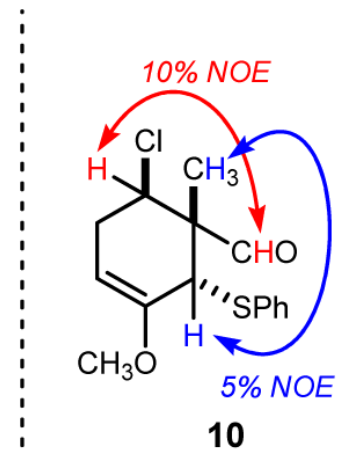

Scheme 2.

Synthesis of the neopentyl cyclohexylchloride using a stereocontrolled [4+2] cycloaddition. 